\title{
A multicentre cross-sectional descriptive study evaluating the cardiovascular risk profile of preoperatively identified patients with hypertension
}

\author{
S Govender, ${ }^{1} \mathrm{MB}$ ChB, DA (SA); C Pfister, ${ }^{1} \mathrm{MB}$ ChB, BSc, DA, DCH; B Rayner, ${ }^{2} \mathrm{MB}$ ChB, FCP (SA), MMed, PhD; \\ R A Dyer, ${ }^{1}$ MB ChB, FCA (SA), PhD; M Flint, ${ }^{1}$ BSc (Medical Physiology), HSc, MSc, PhD; F Roodt, ${ }^{3}$ MB ChB, FCA (SA); \\ J Davids, ${ }^{3} \mathrm{MB}$ ChB, DA (SA), FCA (SA), MMed (Anaes); M B Nejthardt, ${ }^{1}$ BSc Hons (Physiology), MB ChB, DA (SA), FCA (SA); \\ J L Swanevelder, ${ }^{1}$ MB ChB, DA (SA), FCA (SA), MMed, FRCA; E Chiu, ${ }^{1,4}$ MB ChB, DA; E Cloete, ${ }^{1,4}$ MB ChB, DA (SA), FCA (SA); \\ V Koller, ${ }^{5} \mathrm{MB}$ ChB, FCA (SA); T Pretorius, ${ }^{5} \mathrm{MB}$ ChB, DA (SA), FCA (SA), MMed (Anaesth); \\ Z Fullerton, ${ }^{6} \mathrm{MB} \mathrm{ChB}$, DA (SA), FCA (SA), MMed (Anaesth); J Roos, ${ }^{7} \mathrm{MB} \mathrm{ChB}, \mathrm{DA}$ (SA), MMed (Anaesth), FCA (SA); \\ R van Zyl, ${ }^{8}$ MB ChB, DA (SA), FCA (SA); B M Biccard, ${ }^{1} \mathrm{MB}$ ChB, MMedSci, FCA (SA), PhD
}

\author{
${ }^{1}$ Department of Anaesthesia and Perioperative Medicine, Groote Schuur Hospital and Faculty of Health Sciences, University of Cape Town, \\ South Africa \\ ${ }^{2}$ Division of Nephrology and Hypertension, Department of Medicine, Groote Schuur Hospital and Faculty of Health Sciences, University of \\ Cape Town, South Africa \\ ${ }^{3}$ Department of Anaesthesiology, George Regional Hospital, George, South Africa \\ ${ }^{4}$ Department of Anaesthesiology, New Somerset Hospital, Cape Town, South Africa \\ ${ }^{5}$ Department of Anaesthesiology, Paarl Provincial Hospital, Paarl, South Africa \\ ${ }^{6}$ Department of Anaesthesiology, Victoria Hospital, Cape Town, South Africa \\ ${ }^{7}$ Department of Anaesthesiology, Mitchell's Plain Hospital, Cape Town, South Africa \\ ${ }^{8}$ Department of Anaesthesiology, Worcester Hospital, Worcester, South Africa
}

Corresponding author: S Govender (govsar@hotmail.com)

Background. The prevalence of hypertension in adults in South Africa (SA) is 35\%. Hypertension is the most important modifiable risk factor for cardiovascular (CV) and chronic kidney disease (CKD) in sub-Saharan Africa. However, $49 \%$ of people are unaware of their blood pressure status. Screening for hypertension prior to surgery provides a unique opportunity to diagnose and treat affected individuals. Furthermore, assessing overall CV risk identifies patients at highest risk for complications, and improves the utilisation of scarce resources. Objectives. To evaluate the CV risk profile of hypertensive patients in the adult population of the Western Cape Province presenting for elective non-cardiac, non-obstetric surgery.

Methods. This report documents the CV risk profile of patients recruited to the HASS-2 study (Hypertension and Surgery Study 2), which was undertaken in seven Western Cape hospitals. Patients were screened for hypertension and pharmacological treatment was initiated or adjusted in patients with stages 1 and 2 disease. Stage 3 patients were referred to a physician. In the present substudy, patients with stages 1 and 2 hypertension were assessed for associated CV risk factors, the presence of target organ damage, and documented CV or kidney disease; they received an overall risk stratification according to the 2018 European Society of Cardiology and the European Society of Hypertension Guidelines.

Results. Sixty-one patients with stage 1 and 12 with stage 2 hypertension were analysed. Established CV disease was present in $13.7 \%$ of the study population, and CKD (eGFR $<60 \mathrm{~mL} / \mathrm{min}$ ) in $10.8 \%$. Seventy-one percent of the study group had a raised body mass index, and $55.9 \%$ underlying metabolic syndrome. Prediabetes and diabetes were present in $16.1 \%$ and $14.5 \%$, respectively. According to the 2018 European guidelines, $34.7 \%$ were at moderate, $33.3 \%$ at high and $16.7 \%$ at very high risk for a $\mathrm{CV}$ event in the following 10 years.

Conclusions. The perioperative period is a critical time during which surgeons, nurses and anaesthetists can influence patients' CV risk of adverse events. This involves appropriate screening, education and treatment. In this study population, nearly 9 out of 10 elective surgical patients with stage 1 or 2 hypertension had CV risk factors placing them at moderate to very high risk. The simultaneous assessment of these additional CV risk parameters, in addition to diagnosis and management of hypertension, may further decrease the health and financial burden in resource-limited facilities in SA, and improve CV outcomes.

S Afr Med J 2021;111(1):74-79. https://doi.org/10.7196/SAMJ.2020.v111i1.14640

Cardiovascular (CV) disease is the leading cause of death worldwide. ${ }^{[1]}$ In 2013 in sub-Saharan Africa alone, there were approximately 1 million associated deaths. ${ }^{[2]}$ Hypertension is the most important modifiable risk factor for preventing CV disease in Africa, but there is a considerable unmet need. According to the late Prof. Bongani Mayosi, it was the 'number one best buy' for preventing heart disease in Africa. ${ }^{[3]}$
There is an estimated $35.1 \%$ prevalence of hypertension in the South African (SA) adult population. However, there are significant deficiencies in management, as $48.7 \%$ of the adult population have never been screened, are unaware of their hypertension status, and are at risk for adverse CV events. ${ }^{[4]}$ Identifying people with hypertension is an important step towards improving treatment of the disease and preventing adverse CV events. 
The perioperative period is an ideal opportunity to screen for hypertension, as measuring blood pressure (BP) before surgery is mandatory. In a recent study, approximately $50 \%$ of patients presenting for non-cardiac elective surgery were identified as having hypertension, of whom $10 \%$ were newly diagnosed, and $40 \%$ were found to have poorly controlled hypertension. ${ }^{[5]}$ Furthermore, there has been a burgeoning epidemic of other CV risk factors (obesity, dyslipidaemia, and dysglycaemia) that cluster with hypertension.

Although there is a direct relationship between adverse CV outcome and raised BP, this is modified by the presence of $\mathrm{CV}$ risk factors (advanced age, smoking, dyslipidaemia, obesity, and diabetes), target organ damage (e.g. left ventricular hypertrophy (LVH), as evidenced by electrocardiogram (ECG) changes), and established CV or kidney disease. For example, a patient with stage 1 hypertension with no risk factors may have a predicted risk of an adverse CV event in the next 10 years of $<1 \%$, but a diabetic patient with end organ damage may have a risk of $>10 \%{ }^{[6]}$

CV risk stratification is fundamental to all hypertension guidelines, since in absolute terms treatment of patients at highest risk will yield the greatest number of events prevented, and those at lowest risk the least. This enables a limited-resource healthcare system to use funds optimally and target other risk factors. The perioperative period presents an ideal opportunity to identify and educate these patients, and improve their treatment.

The primary objective was to describe the comorbid risk profile of hypertensive patients identified in the recent Hypertension and Surgery Study 2 (HASS-2) conducted in Western Cape Province, SA. ${ }^{[7]}$ This substudy involved identifying CV risk factors, target organ damage, and established CV and kidney disease, in newly diagnosed or poorly controlled hypertensive patients.

\section{Methods}

This is a substudy of HASS-2. Briefly, HASS-2 was a multicentre cross-sectional study conducted at seven hospitals in Western Cape Province, SA: Groote Schuur (a tertiary referral hospital); and six level two institutions, namely George, Mitchells Plain, New Somerset, Paarl, Victoria and Worcester hospitals. Data were collected over a period of 5 working days by anaesthesia medical officers, registrars and specialists, as well as personnel from nursing and surgical departments involved in patient management. Adult patients presenting for elective non-cardiac and non-obstetric surgery were recruited. The inclusion criteria were age $\geq 18$ years, and stage 1 and stage 2 hypertension as defined by the South African Hypertension Practice Guideline 2014 (Table 1). ${ }^{[8]}$

Patients were excluded if they declined to participate in the study, were scheduled for day case procedures, local ophthalmic procedures, obstetric or cardiac surgery, or had normal, high-normal BP or stage 3 hypertension as defined by the South African Hypertension Guideline 2014. Stage 3 patients were referred to a physician for further management.

All consenting patients presenting at the in-hospital preoperative visit the day before their surgery were screened for hypertension, using a validated automated device. The BP measurements were conducted by both nursing staff and anaesthetists the day prior to surgery, to mitigate the effect of anxiety. This was done in accordance with recommendations in the Joint Guidelines from the Association of Anaesthetists of Great Britain and Ireland and the British Hypertension Society. ${ }^{[9]}$

The present substudy was approved by the Human Research Ethics Committee of the Faculty of Health Sciences of the University of Cape Town (ref. no. HREC REF 830/2018), and the Western Cape Department of Health. All centres involved had institutional approval granted. The study was registered on ClinicalTrials.gov (ref. no. NCT03921086). All patients provided written informed consent and the Revised Standards for Quality Improvement Reporting (SQUIRE) were followed. ${ }^{[10]}$

Height, weight, and waist circumference were measured, and body mass index (BMI) calculated. Normal weight was defined as BMI $<25$, overweight $25-30$, and obese $>30 \mathrm{~kg} / \mathrm{m}^{2}$.

The following investigations were performed on patients included in the study, to assess overall CV risk prior to surgery: fasting lipogram, fasting blood glucose, HbAlc, sodium, potassium, creatinine, haemoglobin, urine dipsticks for proteinuria, and ECG.

The American Diabetes Association criteria were used to classify prediabetes and diabetes. Diabetes was defined as HBA1c $\geq 6.5 \%$ or fasting glucose $\geq 7 \mathrm{mmol} / \mathrm{L}$, and prediabetes as $\mathrm{HbAlc}$ between $5.7 \%$ and $6.4 \%$ or fasting glucose between $5.6 \mathrm{mmol} / \mathrm{L}$ and $6.9 \mathrm{mmol} / \mathrm{L}$. The American Heart Association/The National Heart, Lung, and Blood Institute criteria were used to define metabolic syndrome (Table 2). ${ }^{[11]}$

The estimated glomerular filtration rate (eGFR) was calculated using the chronic kidney disease-epidemiology collaboration equation (CKD-EPI), and kidney disease was staged from 1 to 5 (Table 3). Urine dipsticks detecting proteinuria $1+$ or more

Table 1. Definition of hypertension according to the South African Hypertension Practice Guideline 2014 ${ }^{[8]}$

\begin{tabular}{lll} 
African Hypertension Practice Guideline & $\mathbf{2 0 1 4}$ \\
Stage & $\begin{array}{l}\text { Systolic blood } \\
\text { pressure }(\mathbf{m m H g})\end{array}$ & $\begin{array}{l}\text { Diastolic blood } \\
\text { pressure }(\mathbf{m m H g})\end{array}$ \\
\hline Optimal & $<120$ & $<80$ \\
Normal & $120-129$ & $80-84$ \\
High-normal & $130-139$ & $85-89$ \\
Stage 1 & $140-159$ & $90-99$ \\
Stage 2 & $160-179$ & $100-109$ \\
Stage 3 & $\geq 180$ & $\geq 110$
\end{tabular}

Table 2. American Heart Association/National Cholesterol Education Program definition of metabolic syndrome ( $\geq 3$ of the criteria below are required)

\begin{tabular}{ll}
\hline Risk factor & Diagnostic threshold \\
\hline Abdominal obesity: men & $>102 \mathrm{~cm}$ \\
Abdominal obesity: women & $>88 \mathrm{~cm}$ \\
Triglycerides & $>1.7 \mathrm{mmol} / \mathrm{L}$ \\
HDL cholesterol: men & $<1.03 \mathrm{mmol} / \mathrm{L}$ \\
HDL cholesterol: women & $<1.3 \mathrm{mmol} / \mathrm{L}$ \\
Blood pressure & $\geq 130 / \geq 85 \mathrm{mmHg}$ \\
Fasting blood glucose & $>5.55 \mathrm{mmol} / \mathrm{L}$
\end{tabular}

Table 3. Stages of CKD

\begin{tabular}{lll}
\hline Stage & Classification & $\begin{array}{l}\text { eGFR range }(\mathbf{m L} / \\
\left.\mathbf{m i n} / \mathbf{1 . 7 3} \mathbf{~ m}^{\mathbf{2}}\right)\end{array}$ \\
\hline Stage 1 & $\begin{array}{l}\text { Kidney damage with normal } \\
\text { function }\end{array}$ & $>90$ \\
Stage 2 & $\begin{array}{l}\text { Kidney damage with mild } \\
\text { CKD }\end{array}$ & $60-89$ \\
Stage 3A & Moderate CKD & $45-59$ \\
Stage 3B & Moderate CKD & $30-44$ \\
Stage 4 & $\begin{array}{l}\text { Severe CKD } \\
\text { Stage 5 }\end{array}$ & Kidney failure \\
CKD = chronic kidney disease; eGFR = estimated glomerular filtration rate.
\end{tabular}


were regarded as significant. Left ventricular hypertrophy (LVH) on ECG was defined according to the Framingham criteria: $\mathrm{R}$ in AVL $>1.1 \mathrm{mV}$; $\mathrm{R}$ in $\mathrm{V} 5$ or $\mathrm{V} 6 \geq 2.5 \mathrm{mV}$, $\mathrm{S}$ in $\mathrm{V} 1$ or $\mathrm{V} 2 \geq 2.5 \mathrm{mV}, \mathrm{S}$ in $\mathrm{V} 1$ or $\mathrm{V} 2+\mathrm{R}$ in $\mathrm{V} 5$ or $\mathrm{V} 6 \geq 3.5 \mathrm{mV}$, or $\mathrm{S}$ in III $+\mathrm{R}$ in $\mathrm{I} \geq 2.5 \mathrm{mV}^{[12]}$

The 10 -year CV risk was calculated using the SCORE system of the European Society of Hypertension and the European Society of Cardiology (ESH/ESC) risk stratification guidelines, which combine elevated $\mathrm{BP}$ measurements, risk factors, target organ damage and overt CV or kidney disease. Low risk was a calculated 10-year SCORE of $<1 \%$, moderate risk $1-5 \%$, high risk $5-10 \%$ and very high risk $>10 \%{ }^{[6,13]}$

Data were anonymously recorded on data capture forms designed for the study, and thereafter captured electronically onto the secured Research Electronic Data Capture (REDCap) data base, with no random verification. Hard copies were filed in the Department of Anaesthesia and Perioperative Medicine of the University of Cape Town.

\section{Statistical analysis}

Data were analysed using the Statistical Package for the Social Sciences (SPSS) version 25 (IBM Corp., USA). Categorical variables were reported as proportions and compared using the $\chi^{2}$ test and Fisher's exact test, as appropriate. Continuous variables were described as mean and standard deviation (SD) or median and interquartile range (IQR) and compared using the $t$-test or one-way analysis of variance.

\section{Results}

The patient recruitment flow chart is shown in Fig. 1. Analysis of CV risk was confined to patients with stages 1 and 2 hypertension. Stage 3 patients were excluded because they were at high risk based on their BP measurements alone. ${ }^{[6]}$ Forty-two (57.5\%) of the 73 patients were known hypertensives and 31 (42.5\%) were newly diagnosed.

The overall baseline demographic details are shown in Table 4 . The mean age was 57 years and $57.5 \%$ were females. Patients with stage 2 hypertension had a higher mean systolic BP (168 v. $151 \mathrm{mmHg}, p=0.001$ ) compared with those with stage 1 . There was no difference in diastolic BP between stages 1 and 2 . With regard to $\mathrm{CV}$ risk factors, $47 \%$ were obese (BMI $\left.>30 \mathrm{~kg} / \mathrm{m}^{2}\right)$, and $24.2 \%$ were overweight (BMI $25-30 \mathrm{~kg} /$ $\mathrm{m}^{2}$ ). Metabolic syndrome was diagnosed in
$55.9 \%$, and prediabetes and diabetes were present in $16.1 \%$ and $14.5 \%$, respectively (9 patients in each stage). Increased waist circumference was found in $84.6 \%$ of females compared with $37.0 \%$ of males.

Key baseline laboratory data pertaining to dyslipidaemia, diabetes and chronic kidney disease are shown in Table 5. The overall mean low-density lipoprotein (LDL) and high-density lipoprotein (HDL) levels were 1.91 and $1.08 \mathrm{mmol} / \mathrm{L}$, respectively. The median eGFR was 96 in stage 1 and $77 \mathrm{~mL} /$ min in stage 2 hypertension $(p=0.14)$.

The presence of target organ damage (TOD), and overt CV and kidney disease is shown in Table 6. Seven patients (10.8\%) had stage $3 \mathrm{CKD}$ and 19 (29.7\%) proteinuria.

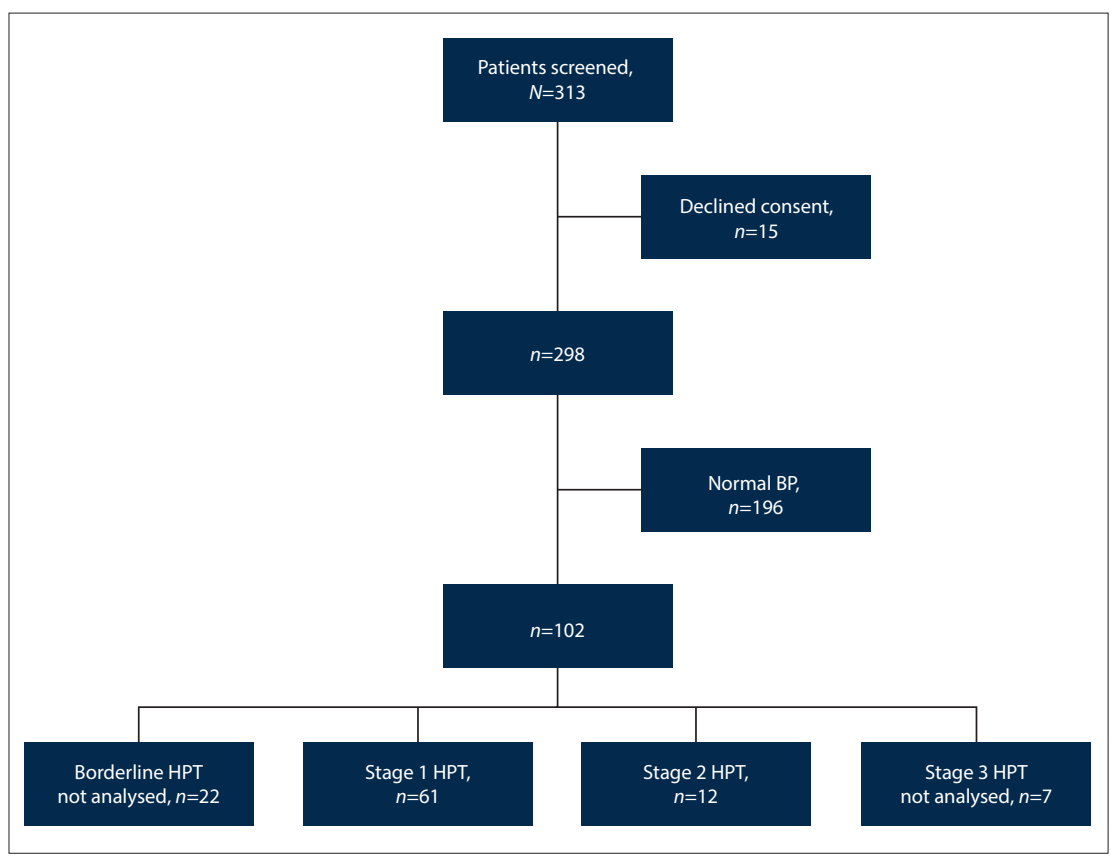

Fig. 1. Flow chart of patient recruitment in seven hospitals $(B P=$ blood pressure; $H P T=$ hypertension $)$.

\begin{tabular}{|c|c|c|c|c|}
\hline Parameter & Overall & Stage $1\left(n=61^{*}\right)$ & Stage $2\left(n=12^{\star}\right)$ & $p$-value \\
\hline Age $(y)$, mean $(S D)$ & $57(13.4)$ & $56(13.1)$ & $62(14.5)$ & 0.166 \\
\hline \multicolumn{5}{|l|}{ Sex, $n(\%)$} \\
\hline Female & $42(57.5)$ & $36(59.0)$ & $6(50.0)$ & \\
\hline Male & $31(42.5)$ & $25(41.0)$ & $6(50.0)$ & 0.751 \\
\hline Systolic BP (mmHg), mean (SD) & $154(11.8)$ & $151(10.6)$ & $168(5.2)$ & $<0.001$ \\
\hline Diastolic BP (mmHg), mean (SD) & $88(10)$ & $87(9.7)$ & $89(11.3)$ & 0.4 \\
\hline \multicolumn{5}{|l|}{ BMI $\left(\mathrm{kg} / \mathrm{m}^{2}\right), n(\%)$} \\
\hline Normal & $19 / 66(28.8)$ & $16 / 54(29.6)^{\dagger}$ & $3(25.0)$ & 0.949 \\
\hline Overweight & $16 / 66(24.2)$ & $13 / 54(24.1)^{\dagger}$ & $3(25.0)$ & 0.949 \\
\hline Obese & $31 / 66(47.0)$ & $25 / 54(46.3)^{\dagger}$ & $6(50.0)$ & 0.949 \\
\hline Waist circumference: female $\geq 88 \mathrm{~cm}, n(\%)$ & $33 / 39(84.6)$ & $27 / 33(81.8)^{\ddagger}$ & $6(100)$ & 0.256 \\
\hline Waist circumference: male $\geq 102 \mathrm{~cm}, n(\%)$ & $10 / 27(37)$ & $9 / 21(42.9)^{\ddagger}$ & $1(16.7)$ & 0.241 \\
\hline Metabolic syndrome, $n(\%)$ & $33 / 59(55.9)$ & $26 / 47(55.3)^{\varsigma}$ & $7(58.3)$ & 1.0 \\
\hline
\end{tabular}




\begin{tabular}{|c|c|c|c|c|}
\hline Parameter & Overall & Stage $1\left(n=61^{\star}\right)$ & Stage $2\left(n=12^{\star}\right)$ & $p$-value \\
\hline LDL (mmol/L), mean (SD) & $1.91(1.26)$ & $1.70(1.14)^{\dagger}$ & $2.39(1.61)$ & 0.093 \\
\hline HDL (mmol/L), mean (SD) & $1.08(0.49)$ & $1.11(0.52)^{\ddagger}$ & $1.27(0.35)$ & 0.310 \\
\hline Triglycerides (mmol/L), mean (SD) & $1.71(0.91)$ & $1.72(0.95)^{\ddagger}$ & $1.66(0.93)$ & 0.846 \\
\hline Pre-diabetes, $n(\%)$ & $9 / 56(16.1)$ & $7 / 45(15.6)^{\varsigma}$ & $2 / 11(18.2)^{9}$ & 0.832 \\
\hline Diabetes, $n(\%)$ & $9 / 63(14.5)$ & $8 / 50(16.0) \|$ & $1(8.3)$ & 0.498 \\
\hline HbAlc \%, mean (SD) & $5.33(2.25)$ & $5.14(2.03)^{\dagger}$ & $5.52(2.71)$ & 0.591 \\
\hline Fasting blood glucose (mmol/L), mean (SD) & $4.95(2.05)$ & $4.83(2.04)^{\varsigma}$ & $4.58(2.24)$ & 0.711 \\
\hline Uric acid (mmol/L), mean (SD) & $0.31(0.13)$ & $0.29(0.12)^{\star *}$ & $0.37(0.10)^{9}$ & 0.58 \\
\hline eGFR (mL/min), median (IQR) & $95(77-109)$ & $96(84-112)$ & $77(64-95)$ & 0.14 \\
\hline Dipstick proteinuria, $n(\%)$ & $19 / 64(29.7)$ & $16 / 53(30.2)^{\dagger \dagger}$ & $3 / 11(27.3)^{9}$ & 0.847 \\
\hline \multicolumn{5}{|c|}{ 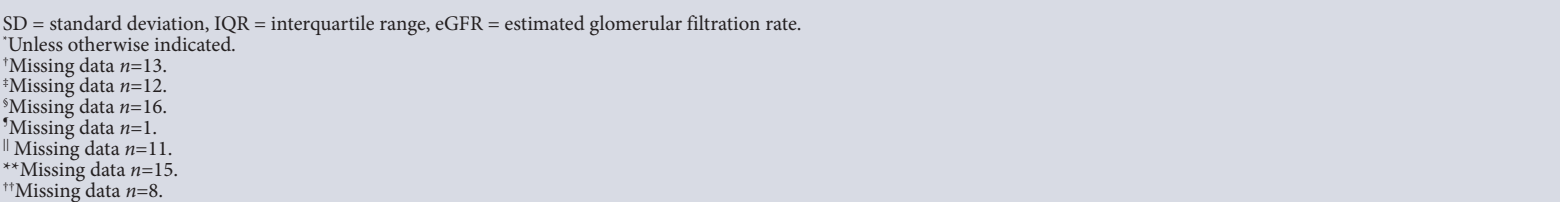 } \\
\hline
\end{tabular}

Table 6. Baseline target organ damage and established $\mathrm{CV}$ disease $\left(N=73^{*}\right)$

\begin{tabular}{|c|c|c|c|}
\hline & Overall & Stage $1\left(n=61^{*}\right)$ & Stage $2(n=12)$ \\
\hline \multicolumn{4}{|l|}{$\mathrm{CKD},{ }^{\dagger} n(\%)$} \\
\hline Stage 1 & $36 / 65(55.4)$ & $32 / 53(60.4)$ & $4(33.3)$ \\
\hline Stage 2 & $22 / 65(33.9)$ & $16 / 53(30.2)$ & $6(50.0)$ \\
\hline Stage 3 & $7 / 65(10.8)$ & $5 / 53(9.4)$ & $2(16.7)$ \\
\hline $\mathrm{LVH}, n(\%)$ & $12 / 60(20.0)$ & $10 / 48(20.8)^{\ddagger}$ & $2(16.7)$ \\
\hline Advanced retinopathy, $n(\%)$ & $4(5.5)$ & $2(3.3)$ & $2(16.7)$ \\
\hline Established CV disease, $n(\%)$ & $10(13.7)$ & $7(11.5)$ & $3(25.0)$ \\
\hline
\end{tabular}

There were no cases of stages 4 or 5 CKD. LVH on ECG, according to Framingham criteria, was present in $20 \%$ of patients.

The risk stratification of patients according to the SCORE system of the ESH/ECS is shown in Table 7. Overall $16.7 \%$ were at very high, $33.3 \%$ high, $34.7 \%$ moderate and $15.2 \%$ low risk for CV events. There were no differences between stages 1 and 2 hypertension, except that there were no low-risk cases in stage 2 patients, since their BP automatically defines them as moderate risk.

\section{Discussion}

\section{Principal findings}

This substudy showed that the coexistence of CV risk factors influences the overall risk stratification of patients with hypertension. Using the SCORE system from the ESH/ESC hypertension guidelines we found that nearly 9 out of 10 elective surgical patients with stages 1 or 2 hypertension have a moderate to very high risk of experiencing $\mathrm{CV}$ events, and 5 out of 10 patients have a high or very high risk. Only $15 \%$ of participants with stage 1 hypertension were classified as low risk according to the SCORE system. The South African Hypertension Practice Guideline ${ }^{[8]}$ advises that these patients may only require lifestyle modification for 3 - 6 months, and antihypertensive therapy if uncontrolled after this period of time. In stage 1 hypertension, $46 \%$ of patients were classified as high or very high risk; this underscores the importance of risk stratification, even in patients with so-called mild hypertension. Recent guidelines have suggested that patients at high risk should be targeted for more intensive BP control if resources permit. In addition, our findings may underestimate $\mathrm{CV}$ risk, as ESH/ESC guidelines recommend multiplying the SCORE risk by
Table 7. Risk stratification of patients

\begin{tabular}{llll}
\hline & $\begin{array}{l}\text { Overall } \\
(\boldsymbol{N}=\mathbf{7 2})\end{array}$ & $\begin{array}{l}\text { Stage 1 } \\
(\boldsymbol{n}=\mathbf{6 0})^{*}\end{array}$ & $\begin{array}{l}\text { Stage 2 } \\
(\boldsymbol{n}=\mathbf{1 2})\end{array}$ \\
\hline Low risk $<1 \%, n(\%)$ & $11(15.2)$ & $11(18.3)$ & 0 \\
Moderate risk 1 - $<5 \%, n(\%)$ & $25(34.7)$ & $21(35.0)$ & $4(33.3)$ \\
High risk 5 - 10\%, $n(\%)$ & $24(33.3)$ & $20(33.3)$ & $4(33.3)$ \\
Very high risk $\geq 10 \%, n(\%)$ & $12(16.7)$ & $8(13.3)$ & $4(33.3)$ \\
${ }^{*}$ Missing data $n=1$. & & &
\end{tabular}

1.3 for people residing in sub-Saharan Africa. However, multiplying the SCORE by 1.3 should be individualised, considering the diverse population of sub-Saharan Africa.

Overall, 7 out of 10 patients were overweight or obese, and 6 out of 10 had underlying metabolic syndrome. Interestingly, abdominal obesity was present in $84.6 \%$ of females v. $37.0 \%$ of males. The high prevalence of these $\mathrm{CV}$ risks suggests that there is considerable opportunity for improving the lifestyle of patients in terms of diet and physical activity. Prediabetes and diabetes were present in $16.1 \%$ and $14.5 \%$, respectively, and the mean $\mathrm{HbAlc}$ level of diabetic patients was suboptimal, which highlights poor disease control and increased risk in those already diagnosed with diabetes. The mean LDL cholesterol was $1.91 \mathrm{mmol} / \mathrm{L}$, which is a surprising result that is not entirely explained. It may represent a negative phase reaction in patients undergoing surgery, ${ }^{[14]}$ or possibly high levels of statin use in the public sector in the Western Cape.

$\mathrm{CV}$ risk is potentially modifiable if risk factors are identified and treated appropriately. In this study established CV disease was 
present in $14 \%$ of patients, unrecognised CKD (eGFR $<60 \mathrm{~mL} / \mathrm{min}$ ) in $11 \%$, proteinuria in $30 \%$, and 1 in 5 patients fulfilled criteria for LVH on ECG. This emphasises the importance of screening patients preoperatively to decrease morbidity.

\section{Implications of the study}

Hypertension is one of the most common comorbidities associated with elective non-cardiac surgery. ${ }^{[5]}$ This, together with additional $\mathrm{CV}$ risk factors, significantly increases the perioperative risk of these patients. ${ }^{[6,13]} \mathrm{CV}$ risk stratification is fundamental to all hypertension guidelines, since in absolute terms treatment of patients at highest risk will yield the greatest number of events prevented, and those at lowest risk the least. This enables a limited-resource healthcare system to use funds optimally and target treatment of these risk factors to prevent CV disease.

In a recent study in the Western Cape, ${ }^{[5]}$ the importance was shown of identifying poorly controlled hypertension and diagnosing new disease in the perioperative period. The present substudy indicates that screening for additional CV risk factors in the perioperative period may improve morbidity and mortality.

$\mathrm{CV}$ disease is a leading cause of death, ${ }^{[1]}$ and in SA the majority of patients are initially assessed in a primary healthcare setting. Excluding age, CV risk factors are generally modifiable. This study has shown that the perioperative period is a key opportunity for the identification of goal-directed screening parameters which can substantially influence the overall health of patients. Initiation of therapy based on abnormalities detected at this time could reduce the burden on already strained secondary and tertiary institutions.

Our findings have particular relevance in view of the increasing burden of non-communicable diseases in sub-Saharan Africa from 1990 to 2017, which includes significant increases in hypertensive and ischaemic heart disease, stroke and CKD. ${ }^{[15]}$

\section{Study strengths and limitations}

A strength of this multicentre investigation was that data collection was performed prior to surgery. This allowed identification of those patients at risk, provided education to both patients and surgical staff, and if necessary, allowed for the referral of patients for further management (specifically stage 3 hypertension) and follow-up.

A limitation of this study was missing data of some of the parameters used to classify $\mathrm{CV}$ risk (inadequate data for diagnosis of metabolic syndrome in 19\%, absent baseline laboratory data in 11 - 18\%, and no ECG diagnosis of LVH in 18\%). eGFR results from the laboratory were not corrected for body surface area. In addition, the data entered into REDCap had no random verification. We do not expect these factors to have resulted in major errors of risk classification, although some minor misclassifications may have been possible. Importantly, we do not believe this would have changed the fundamental message of this work, which is that hypertensive patients who present for elective surgery in the Western Cape predominantly have an important CV risk profile.

Further limitations of the study were that there were no data captured on the prevalence of smoking, and use of statins was not recorded in the questionnaire. Day case surgery was also excluded in the screening process of HASS-2, thereby possibly missing undiagnosed or poorly controlled hypertension. Further research involving larger study populations would be beneficial to substantiate the findings of this substudy.

\section{Conclusions}

The perioperative period is a significant period during which surgeons, nurses and anaesthetists can influence patients' CV risk of adverse events. This involves appropriate screening, education and treatment. The ultimate goal is to improve the overall lifestyle, pharmacological management and health of the SA population. The simultaneous assessment of CV risk factors, in addition to diagnosis and management of hypertension, may further decrease the health and financial burden in resource-limited facilities in SA, and improve CV outcomes.

\section{Declaration. None.}

Acknowledgments. The authors acknowledge and thank the Provincial Government of the Western Cape for its role in this multicentre research study, as well as the involvement of the theatre and ward staff in all seven public sector hospitals. We thank the site co-ordinators (anaesthetists) at the participating centres, New Somerset, Paarl, Victoria, Mitchell's Plain, Worcester, and George hospitals. We also thank the Department of Anaesthesia and Perioperative Medicine at Groote Schuur Hospital for accommodating logistic and roster changes necessary to make this study possible.

Author contributions. This submission has 17 authors from a multicentre cross-sectional observational study conducted at seven Western Cape hospitals. All authors (SG, CP, BR, RD, MF, FR, JD, MN, JS, EC, EC, VK, $\mathrm{TP}, \mathrm{ZF}, \mathrm{JR}, \mathrm{RvZ}$ and $\mathrm{BB}$ ) were involved in the overall conception and execution of the study, as well as the interpretation, drafting and critical revision of the work, and final approval of the version to be published, and agreed to be accountable for all aspects, accuracy and integrity of the work. FR and JD were responsible for data collection at George Hospital, EC and EC at Somerset Hospital, VK and TP at Paarl Hospital, ZF at Victoria Hospital, SG and CP at Groote Schuur Hospital, JR at Mitchell's Plain Hospital, and RvZ at Worcester Hospital.

Funding. Funding for this study was received from the South African Society of Anaesthesiologists (SASA)'s Jan Pretorius Research Fund. Resources of the Department of Anaesthesia and Perioperative Medicine at Groote Schuur Hospital were utilised.

Conflicts of interest. None.

1. Lee ES, Vedanthan R, Jeemon P, et al. quality improvement for cardiovascular disease care in lowand middle-income countries: A systematic review. PLoS ONE 2016;11(6):e0157036. https://doi. Keates AK, Mocumbi

2. Keates AK, Mocumbi AO, Ntsekhe M, Sliwa K, Stewart S. Cardiovascular disease in Africa: Epidemiological profile and challenges. Nat Rev Cardiol 2017;14(5):273-293. https://doi.org/10.1038/ nrcardio. 2017.19

3. Mayosi BM. The 10 'Best Buys' to combat heart disease, diabetes and stroke in Africa. Heart 2013;99(14):973-974. https://doi.org/10.1136/heartjnl-2013-304130

4. Berry KM, Parker WA, McHiza ZJ, et al. Quantifying unmet need for hypertension care in South Africa through a care cascade: Evidence from the SANHANES, 2011-2012. BMJ Glob Health 2017;2(3):e000348. https://doi.org/10.1136/bmjgh-2017-000348

5. Van der Spuy K, Crowther M, Nejthardt M, et al. A multicentre, cross-sectional study investigating the prevalence of hypertensive disease in patients presenting for elective surgery in the Western Cape Province, South Africa. S Afr Med J 2018;108(7):590-595. https://doi.org/10.7196/SAMJ.2018. v108i7.13022

6. Williams B, Mancia G, Spiering W, et al. 2018 Practice Guidelines for the management of arterial hypertension of the European Society of Hypertension and the European Society of Cardiology: ESH/ ESC Task Force for the Management of Arterial Hypertension. J Hypertens 2018;36(12):2284-2309. https://doi.org/10.1097/hjh.0000000000001961

7. Pfister C-L, Govender S, Dyer RA, et al. A multicenter, cross-sectional quality improvement project: The perioperative implementation of a hypertension protocol by anesthesiologists. Anesth Analg 2020;131(5):1401-1408. https://doi.org/10.1213/ane.000000000000496

8. Seedat YK, Rayner BL, Veriava Y. South African Hypertension Practice Guideline 2014. Cardiovasc J Afr 2014;25(6):288-294. https://doi.org/10.5830/cvja-2014-062

9. Hartle A, McCormack T, Carlisle J, et al. The measurement of adult blood pressure and management of hypertension before elective surgery: Joint Guidelines from the Association of Anaesthetists of Great Britain and Ireland and the British Hypertension Society. Anaesthesia 2016;71(3):326-337. https://doi. org/10.1111/anae. 13348

10. Ogrinc G, Davies L, Goodman D, et al. SQUIRE 2.0 (Standards for Quality Improvement Reporting Excellence): Revised publication guidelines from a detailed consensus process. BMJ Qual Sa 2016;25(12):986-992. https://doi.org/10.1136/bmjqs-2015-004411

11. Grundy SM, Cleeman JI, Daniels SR, et al. Diagnosis and management of the metabolic syndrome: An American Heart Association/National Heart, Lung, and Blood Institute Scientific Statement. Circulation 2005;112(17):2735-2752. https://doi.org/10.1161/circulationaha.105.169404

12. Van Kleef M, Visseren FLJ, Vernooij JWP, et al. Four ECG left ventricular hypertrophy criteria and the risk of cardiovascular events and mortality in patients with vascular disease. J Hypertens 2018;36(9):1865-1873. https://doi.org/10.1097/hjh.0000000000001785 
13. Mancia G, Fagard R, Narkiewicz K, et al. 2013 ESH/ESC Guidelines for the management of arterial hypertension: The Task Force for the management of arterial hypertension of the European Society of Hypertension (ESH) and of the Europen 1357. https://doi.org/10.1097/01.hjh.0000431740.32696.cc 4. Khovidhunkit W, Kim MS, Memon RA, et al. Effects of infection and inflammation on lipid an lipoprotein metabolism: Mechanisms and consequences to the host. J Lipid Res 2004;45(7):1169-1196. https://doi.org/10.1194/jlr.r300019-jlr200
15. Gouda HN, Charlson F, Sorsdahl K, et al. Burden of non-communicable diseases in sub-Saharan Africa, 1990-2017: Results from the Global Burden of Disease Study 2017. Lancet Glob Health 2019;7(10):el375-1387. https://doi.org/10.1016/s2214-109x(19)30374-2

Accepted 14 April 2020. 